\title{
Unemployment and mortality among Finnish men, 1981-5
}

\author{
Pekka T Martikainen
}

\begin{abstract}
Objective-To ascertain whether, after controlling for several relevant background variables simultaneously, unemployment is related to mortality and to assess whether this relation is causal or whether unhealthy people are more likely to become unemployed.
\end{abstract}

Design-Prospective study of mortality in Finland during 1981-5 based on 1980 census data on 30-54 year old wage earner men and with particular attention to unemployment in the year before the census.

Setting-Research project at the University of Helsinki.

Subjects - All wage earner men in Finland aged 3054 at the 1980 census.

Main outcome measures-Causes of death during 1981-5 and duration of unemployment in the year before the census. Background variables controlled for were age, socioeconomic state, marital state, and health. The data were analysed by log linear regression models.

Results-During the study period 1981-5, which covered almost 2.7 million person years, there were 9810 deaths. After controlling for all background variables relative total mortality among unemployed versus employed men was 1.93 (95\% confidence interval 1.82 to 2.05 ). The excess mortality was highest in accidental and violent causes of death (relative mortality $2 \cdot 51 ; 95 \%$ confidence interval 2.28 to $2 \cdot 76$ ). For circulatory diseases the relative death rate was $1.54(95 \%$ confidence interval 1.40 to 1.70$)$, but among neoplasms only lung cancer was associated with excess mortality. Selection for unemployment based on age, socioeconomic state, and marital state was evident but no such selection was detected based on health. Effects of unemployment on mortality were more pronounced with increasing duration of unemployment.

Conclusions-The relative excess mortality of unemployed men in Finland cannot fully be explained by demographic, social, and health variables preceding unemployment. Unemployment therefore seems to have an independent causal effect on male mortality. Further studies are needed to elucidate the mechanisms between unemployment and mortality.

\section{Introduction}

The relation between unemployment and mortality has been the subject of several studies during high levels of unemployment. Findings during the 1930s and from the end of the 1970s, however, have been inconclusive. Moser et al analysed a data sample from the 1971 census in England and Wales and concluded: “Among men who were 'seeking work' in 1971, our data indicate high mortality (SMR 136) over the next 10 years. The analysis suggests that some of this excess mortality may be explained by the fact that unemployed men were more concentrated in social classes IV and V; none the less, a $20-30 \%$ excess remained unexplained. However, it should be noted that, without details of the timing of unemployment in relation to social mobility, it is difficult to establish the direction of the causal relation."'

This quotation from Moser et al brings out the central problem: although in many studies mortality among the unemployed is higher than that among employed people, ${ }^{1.5}$ it is still not clear whether unemployment is causing excess mortality or whether some background variables are causing both unemployment and mortality. In the second case the interdependence between unemployment and mortality does not reflect the causal effects of unemployment.

The observed interdependence betweeen unemployment and mortality may thus be explained in two ways. ${ }^{6}$ Firstly, according to the selection hypothesis (fig 1) the interdependence between unemployment and mortality is spurious. This hypothesis is valid only

\section{Selection hypothesis}

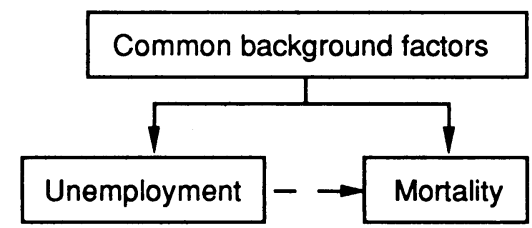

\section{Causal explanation}

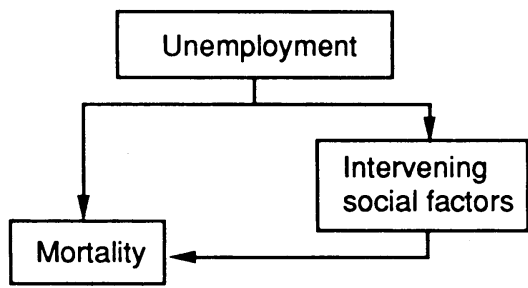

FIG 1-Two models explaining interdependence between unemployment and mortality

if unemployment and mortality are associated with common background factors. A spurious interdependence arises when the risk of becoming unemployed is higher than average in population groups that also have a high mortality. This kind of interdependence is not causal, and in this case unemployment cannot be considered to be a causal determinant of mortality.

Selection may be based on various factors. Poor health can in itself cause unemployment or inability to work full time. An employer may be more likely to dismiss workers who are not able to work to expected standards. Furthermore, poor education and low socioeconomic state are associated with high risk of unemployment. ${ }^{7}$ Because these factors are also known 
to affect mortality, ${ }^{8}$ it is clear that the interdependence between unemployment and mortality is at least partly spurious. Selection based on age, marital state, and region of residence is also possible.

The second explanation is causal (fig 1). Unemployment affects mortality directly or through intervening social factors. In the second case unemployment affects factors which in their own right affect mortality. Many such intervening factors have been described, some of the most common being fall in income and socioeconomic state, increased stress, disruption of social networks, and unstable lifestyle. ${ }^{129}$

The Finnish census linked mortality data, which include several variables describing health, social state, and duration of unemployment, offer a possibility to shed new light on the central problem of direction of causation. This study therefore aimed at assessing whether unemployment is related to mortality when several relevant background variables are simultaneously controlled for. Mortality was analysed according to cause of death and duration of unemployment.

\section{Subjects and methods}

The study was based on the 1980 census records in Finland linked with all deaths during 1981-5 and certain variables from the 1970 and 1975 censuses. In addition, variables that measure health and income were linked from the data files of the Social Insurance Institution and the National Board of Taxation. The linkage of data sets was carried out by the Central Statistical Office of Finland by means of personal identification codes. The analysis concerned men in the labour force who were aged 30-54 at the time of the census. Only wage earners were included. The number of person years covered by the study totalled almost $2 \cdot 7$ million. Men under 30 were excluded because a large proportion were still students and thus not in the labour force. Men over 55 were excluded because of the number who retired early on health grounds. Table I lists the variables and classifications used in the analysis.

The data were cross tabulated against all variables included in the analysis. In the resulting contingency table each cell includes information on the number of deaths and the number of person years covered during 1981-5. The table was analysed by log linear regression analysis. The generalised linear interactive modelling (GLIM) statistical package was used in fitting the models. ${ }^{10}$ The following model described the relation between mortality and the explanatory variables:

$$
\log \left(E\left(d_{i}\right) / V_{i}\right)=a+b_{1} x_{i 1}+b_{2} x_{i 2}+\ldots+b_{p} x_{i p}
$$

where $E\left(d_{i}\right)$ was the expected number of deaths in the $i^{\text {th }}$ cell, $V_{i}$ was the number of person years in the $\mathrm{i}^{\text {th }}$ cell, $\mathrm{x}_{1}, \ldots, \mathrm{x}_{\mathrm{p}}$ were the explanatory variables, and $a, b_{1}, \ldots, b_{p}$ were the parameters to be estimated. ${ }^{112}$ The models were fitted in succession starting with a model including unemployment as the only explanatory variable and then adding background variables consecutively. The duration of unemployment during the year before the census was known for all subjects. The background variables were added to the model according to their causal order-namely, age, socioeconomic state (from the 1975 census), education and marital state (from the 1975 census), and health variables (from the 1980 census). Contextual variables were also included in the model-for example, level of unemployment, region, and regional developmentbut as their effects on the interdependence between unemployment and mortality were not significant they are not considered further.

The results of the log linear regression models are

TABLE I-Numbers of person years covered by study, numbers of deaths, death rates, standardised mortality ratios, and percentages of men unemployed according to variables included in analysis

\begin{tabular}{|c|c|c|c|c|c|}
\hline & $\begin{array}{l}\text { No of person years } \\
\left(\times 10^{3}\right)\end{array}$ & No of deaths 1981-5 & No of deaths $/ 100000$ & $\begin{array}{l}\text { Standardised } \\
\text { mortality ratio }\end{array}$ & $\%$ Unemployed \\
\hline \multicolumn{6}{|c|}{ Duration of unemployment (months): } \\
\hline $1-3$ & 75 & 379 & 505 & 140 & - \\
\hline $4-6$ & 56 & 437 & 780 & 201 & - \\
\hline $7-11$ & 40 & 430 & 1075 & 274 & - \\
\hline 12 & 31 & 441 & 1423 & 326 & - \\
\hline All unemployed men & 202 & 1687 & 835 & 216 & - \\
\hline All employed men & 2475 & 8123 & 328 & 90 & - \\
\hline \multicolumn{6}{|l|}{ Age (years): } \\
\hline $50-54$ & 371 & 3369 & 908 & - & $9 \cdot 2$ \\
\hline $45-49$ & 420 & 2206 & 525 & - & $8 \cdot 1$ \\
\hline $40-44$ & 495 & 1709 & 345 & - & $7 \cdot 2$ \\
\hline $35-39$ & 611 & 1313 & 215 & - & $6 \cdot 3$ \\
\hline $30-34$ & 781 & 1213 & 155 & - & $7 \cdot 9$ \\
\hline \multicolumn{6}{|c|}{ Socioeconomic state (census 1975): } \\
\hline Upper white collar & 464 & 1120 & 241 & 66 & $1 \cdot 6$ \\
\hline Lower white collar & 610 & 1832 & 300 & 85 & $3 \cdot 4$ \\
\hline Skilled workers & 1218 & 4725 & 388 & 107 & $7 \cdot 6$ \\
\hline Skilled workers in hi & & & & & \\
\hline occupations & 230 & 1142 & 497 & 127 & $19 \cdot 9$ \\
\hline Unskilled workers & 154 & 991 & 644 & 157 & $23 \cdot 6$ \\
\hline \multicolumn{6}{|l|}{ Years of education: } \\
\hline$<10$ & 1349 & 6381 & 473 & 114 & $10 \cdot 1$ \\
\hline $10-12$ & 968 & 2689 & 278 & 91 & $6 \cdot 4$ \\
\hline$>12$ & 360 & 740 & 206 & 60 & $1 \cdot 6$ \\
\hline \multicolumn{6}{|c|}{ Marital state (census 1975): } \\
\hline Single & 469 & 1945 & 415 & 152 & $15 \cdot 0$ \\
\hline Married & 2086 & 7009 & 336 & 87 & $5 \cdot 4$ \\
\hline Separated & 22 & 121 & 550 & 154 & $14 \cdot 4$ \\
\hline Divorced & 91 & 644 & 708 & 179 & $18 \cdot 7$ \\
\hline Widowed & 8 & 91 & 1138 & 179 & $11 \cdot 4$ \\
\hline \multicolumn{6}{|c|}{ Use of reimbursable medicines ${ }^{\star}$ : } \\
\hline None & 2466 & 7812 & 317 & 89 & $7 \cdot 6$ \\
\hline For mental diseases & 9 & 100 & 1111 & 274 & $21 \cdot 1$ \\
\hline For other diseases & 201 & 1898 & 944 & 183 & $7 \cdot 6$ \\
\hline \multicolumn{6}{|c|}{ No of sick allowance days: } \\
\hline None & 2335 & 7445 & 319 & 89 & $7 \cdot 6$ \\
\hline $1-7$ & 126 & 607 & 482 & 125 & $5 \cdot 3$ \\
\hline $8-28$ & 137 & 804 & 587 & 143 & $7 \cdot 6$ \\
\hline $29-330$ & 80 & 954 & 1193 & 264 & $12 \cdot 7$ \\
\hline Total & 2677 & 9810 & 367 & 100 & $7 \cdot 6$ \\
\hline
\end{tabular}

${ }^{\star}$ Medicines for which patients entitled to full reimbursement of cost. 
TABLE II - Relative death rates by cause of death among unemployed wage earner men aged 30-54 after controlling for age alone and for age plus all other background variables (socioeconomic state, education, marital state, reimbursable medicines, number of sick allowance days)

\begin{tabular}{|c|c|c|c|}
\hline \multirow[b]{2}{*}{ Causes of death ${ }^{\star}$} & \multirow[b]{2}{*}{$\begin{array}{l}\text { Age controlled } \\
\text { relative mortality }\end{array}$} & \multicolumn{2}{|c|}{$\begin{array}{l}\text { After controlling for age plus all other } \\
\text { background variables }\end{array}$} \\
\hline & & Relative mortality & $\begin{array}{l}\text { Approximate } 95 \% \\
\text { confidence interval }\end{array}$ \\
\hline \multicolumn{4}{|l|}{ Diseases: } \\
\hline Malignant neoplasms (ICD 140-239) & 1.39 & $1 \cdot 17$ & 1.00 to 1.37 \\
\hline Stomach cancer (ICD 151) & $1 \cdot 18$ & 1.06 & 0.66 to 1.73 \\
\hline Lung cancer (ICD 162) & $2 \cdot 05$ & $1 \cdot 43$ & $1 \cdot 12$ to 1.85 \\
\hline Cancer of intestine and rectum & & & \\
\hline (ICD 153-154) & 1.42 & $1 \cdot 60$ & 0.95 to 2.99 \\
\hline Other cancers & $1 \cdot 07$ & 0.95 & 0.75 to 1.21 \\
\hline Circulatory diseases (ICD 390-458) & 1.87 & 1.54 & 1.40 to 1.70 \\
\hline Acute myocardial infarction (ICD 410) & $1 \cdot 62$ & $1 \cdot 36$ & 1.18 to 1.56 \\
\hline Other ischaemic heart disease & & & \\
\hline (ICD 411-415) & $2 \cdot 18$ & $1 \cdot 77$ & $1 \cdot 44$ to $2 \cdot 17$ \\
\hline Cerebrovascular disease (ICD 430-438) & $1 \cdot 94$ & 1.54 & 1.21 to 1.96 \\
\hline Other circulatory diseases & $2 \cdot 49$ & $2 \cdot 08$ & 1.59 to 2.72 \\
\hline Diseases of respiratory system (ICD & & & \\
\hline 460-493) & $4 \cdot 78$ & $3 \cdot 32$ & $2 \cdot 14$ to $5 \cdot 13$ \\
\hline Alcohol related diseases (ICD 291, 303, & & & \\
\hline 571,577$) \dagger$ & $5 \cdot 80$ & $5 \cdot 24$ & $4 \cdot 21$ to $6 \cdot 52$ \\
\hline Other diseases & $2 \cdot 90$ & $2 \cdot 67$ & $2 \cdot 03$ to 3.51 \\
\hline Total (ICD 1-796) & $2 \cdot 03$ & $1 \cdot 70$ & 1.58 to 1.83 \\
\hline \multicolumn{4}{|l|}{ Accidents and violence: } \\
\hline Suicide (ICD E950-E959) & $2 \cdot 61$ & 1.92 & 1.62 to 2.27 \\
\hline Traffic accidents (ICD E800-E846) & $2 \cdot 53$ & $1 \cdot 88$ & 1.47 to $2 \cdot 40$ \\
\hline Alcohol poisonings (ICD E860) & 6.98 & $4 \cdot 62$ & 3.59 to 5.95 \\
\hline Other accidents and violence & $4 \cdot 09$ & $3 \cdot 01$ & $2 \cdot 54$ to $3 \cdot 56$ \\
\hline Total (ICD E800-E999) & $3 \cdot 45$ & $2 \cdot 5.1$ & $2 \cdot 28$ to $2 \cdot 76$ \\
\hline Total mortality (ICD 1-999) & $2 \cdot 41$ & 1.93 & 1.82 to 2.05 \\
\hline
\end{tabular}

*Causes of death classified according to International Classification of Diseases (ICD) codes (eighth revision). †Alcohol psychosis, alcoholism, cirrhosis of liver, pancreatitis.

presented as relative death rates (relative mortality). The first category of each explanatory variable is taken as a reference point with a relative rate of one. Standardised mortality ratios are presented in table I to permit comparisons with other studies.

\section{Results}

TOTAL MORTALITY

When the unemployment variable was treated as a dichotomy (employed-unemployed) the total mortality among men unemployed for any period during the year before the census was 2.54 times that among men employed for the whole year. This excess mortality among unemployed men fell by almost $40 \%$ when all background variables were simultaneously controlled for. None the less, a relative excess mortality of 1.93 remained. The most important variables explaining the excess mortality among the unemployed were age, socioeconomic state, and marital state, which contributed $5 \%, 11 \%$, and $9 \%$ of the excess respectively. Controlling for health variables had no appreciable impact on the relation between unemployment and mortality.

Figure 2 shows the change in relative mortality among unemployed men when background variables were added to the model. Controlling for education had practically no effect on the interdependence between unemployment and mortality owing to the strong correlation between socioeconomic state and education.

Men may react differently to unemployment depending on their life situation in general. For example, it has been suggested that single men without a family and supporting social contacts suffer most from the consequences of unemployment and that men in lower educational and socioeconomic groups are most vulnerable because of poor financial resources. ${ }^{1314}$ An analysis of data not presented here, however, suggested that only men in young age groups and healthy men suffered particularly from the consequences of unemployment. Unemployment increased their mortality some $30-40 \%$ more than it did among men who were old or unhealthy. Especially interesting was that unemployment increased mortality similarly in all marital states. When studying the above relations all background variables included in the data (see table I) were controlled for.

\section{CAUSES OF DEATH}

When all background variables were controlled for the relative mortality among unemployed men was higher from accidents and violence than from diseases $(2.51 v 1.70$; table II). Controlling for the background variables reduced the excess mortality of the unemployed by about $32 \%$ with respect to diseases and $38 \%$ with respect to accidents and violence. As in total mortality the most important controlling variables were age, socioeconomic state, and marital state (fig 3 ).

Table II gives the relative death rates among the unemployed men by causes of death coded according to the International Classification of Diseases (eighth revision). Excess mortality fell by $10-60 \%$ with respect to the various causes when all background variables

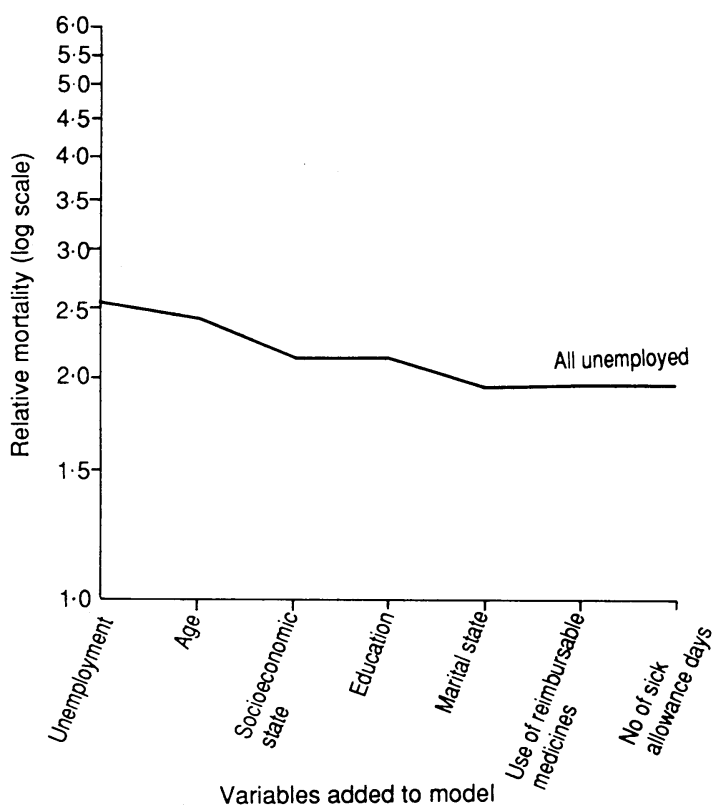

FIG 2-Change in relative mortality from all causes when adding variables to model

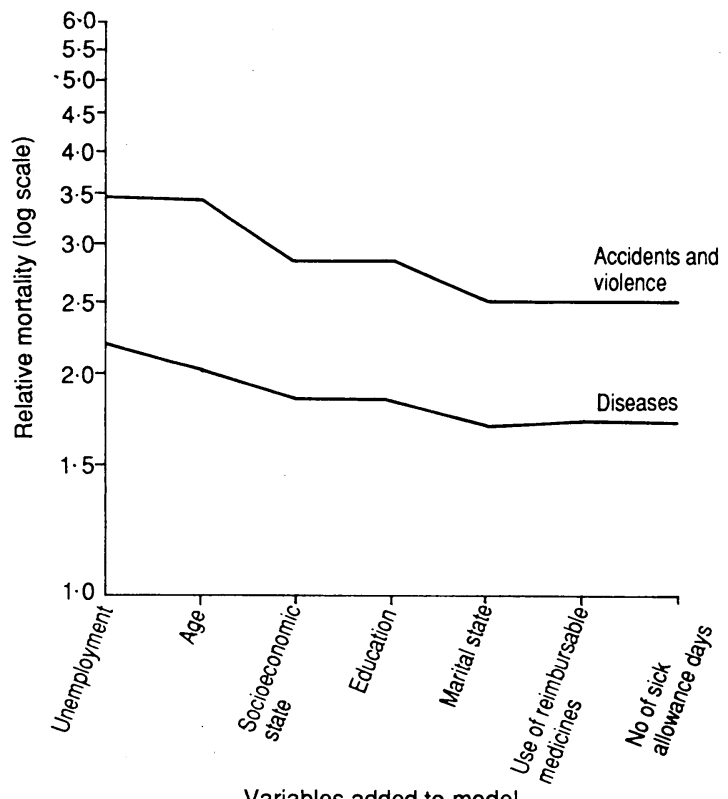

FIG 3-Change in relative mortality from two broad causes when adding variables to model 
were controlled for. The highest relative mortality was associated with alcohol related diseases and alcohol poisonings. The data, however, included no information on alcohol consumption. Hence some of the excess mortality from alcohol related diseases and alcohol poisonings was probably caused by heavy drinkers being more likely to become unemployed.

Unemployment was associated with a $92 \%$ increase in mortality from suicide after controlling for all background variables. Controlling for use of reimbursable medicines (that is, medicines for which subjects are entitled to full reimbursement of cost) lowered the excess mortality by about $4 \%$. This was because the mortality from suicide was fourfold among men using these medicines for mental diseases.

The excess mortality from cancer among unemployed men was only $17 \%$. Only mortality from lung cancer was appreciably increased (relative mortality $1 \cdot 43$; $95 \%$ confidence interval $1 \cdot 12$ to $1 \cdot 85$ ). This result differs from the results of Moser et al, who found that the excess mortality from lung cancer among unemployed men was as high as the excess mortality from accidents and violence.

Excess mortality was much higher from circulatory diseases than from cancer. The overall relative mortality from circulatory diseases among unemployed as compared with employed men was 1.54 (95\% confidence interval 1.40 to $1 \cdot 70$ ). For acute myocardial infarction the relative mortality was $1 \cdot 36$. The role of health related selection in the excess mortality from this condition was probably rather small because many of those who died of acute myocardial infarction had previously been healthy.

The high excess mortality from respiratory diseases among unemployed men (relative mortality 3.32 ) was probably partly explained by homeless alcoholics being more likely to be unemployed. Excess deaths from this cause occurred only in groups unemployed for more than seven months.

\section{DURATION OF UNEMPLOYMENT}

The relative mortality from all causes increased with the duration of unemployment (fig 4). A non-causal

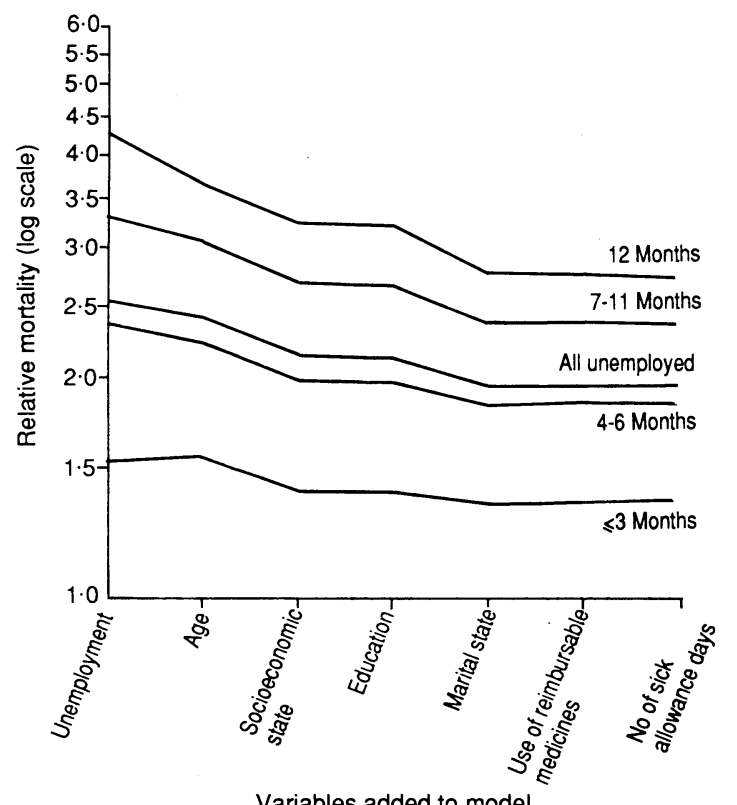

FIG 4-Change in relative mortality from all causes when adding new variables to model by duration of unemployment

way of interpreting the interrelation between duration of unemployment and mortality is to consider it in terms of the selection hypothesis - that is, men with the highest risk of death are more likely to be unemployed for long periods. The data, however,

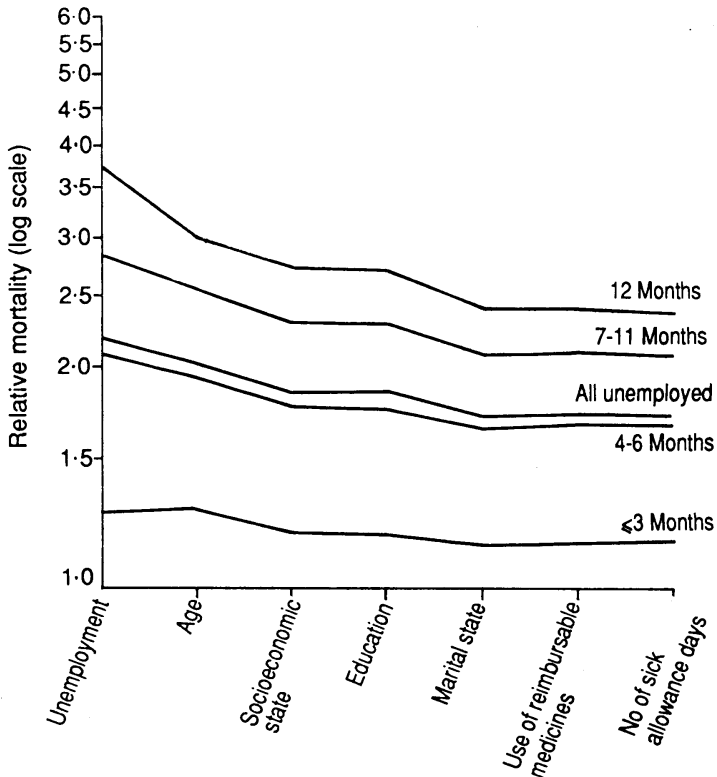

Variables added to model

FIG 5-Change in relative mortality from diseases when adding new variables to model by duration of unemployment

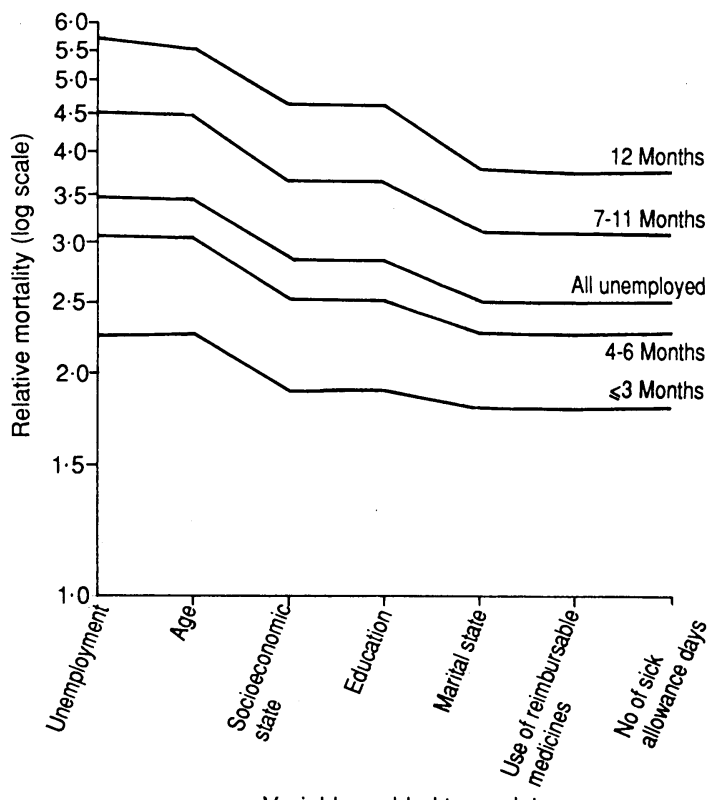

Variables added to mode

FIG 6-Change in relative mortality from accidents and violence when adding new variables to model by duration of unemployment

give only limited support. If selection had taken place controlling for background variables would have made the relative death rates of groups with different durations of unemployment converge. This did not occur to any great extent (see figs 4-6), and after controlling for all background variables clear differences between groups with different durations of unemployment remained. Excess mortality from diseases among men unemployed for one to three months was only slight and may have been a result of random variation (fig 5). With respect to accidents and violence the relative mortality was well above 1.5 with all durations of unemployment (fig 6).

\section{Discussion}

COMPARISONS WITH OTHER CENSUS BASED STUDIES

This study differed from those of Moser $e a \mathrm{al}^{134}$ and Iversen $e t a l^{5}$ in two main ways. Firstly, the data included many relevant background variables, which made it possible to control for selection based on social 
state and (to some extent) health. Secondly, the data included information on the duration of unemployment for up to one year before the census.

The main results corresponded quite well with those of Moser et al and Iversen et al and were clearly different in only two respects. Firstly, this study found a low excess mortality from cancer among unemployed men, whereas Moser et al found a high excess mortality. ${ }^{1}$ The disparity was probably due to differences in data and national characteristics, but it may also reflect the inability of Moser et al to control for some background variables which were controlled for in this study. In this study standardising for several background variables reduced the excess mortality from lung cancer by around $60 \%$ (from a relative mortality of 2.05 to 1.43 ). This was as expected because in Finland smoking is very common in lower socioeconomic and educational groups and among the widowed, ${ }^{15}$ who are also overrepresented among the unemployed.

The second difference was in the total excess mortality recorded among unemployed men, which was higher in Finland than in England and Wales and Denmark. This may also have been due partly to differences in the age range and composition of the populations studied. On the other hand, Finnish men may react more extremely to unemployment owing to different attitudes to paid work and the role of the man as the supporter of his family.

\section{SELECTION HYPOTHESIS}

Selection based on variables measuring demographic and social characteristics was taking place but seemed to be only partly responsible for the high mortality among the unemployed. Controlling for all background variables simultaneously reduced the excess mortality by some $10-60 \%$ depending on the cause of death and duration of unemployment. Nevertheless, a relative excess mortality of 1.93 remained and was unexplained. The data do not support the hypothesis of strong health related selection. ${ }^{2}$ Only small marginal groups-the mentally ill and people who had had more than 28 sick allowance days-were overrepresented among the unemployed (table I). Although the health variables measured only limited aspects of health and their distributions were skewed, they certainly measured the vulnerability of subjects in a consistent way: mortality increased as the number of sick allowance days increased and with the use of reimbursable medicines.

\section{Conclusions}

The three main findings of this study may be summarised as follows. Firstly, the excess mortality among unemployed men remained high after controlling for age, social state, marital state, and certain measures of health. Selection based on age, socioeconomic state, and marital state was evident but no such selection was detected based on health. Secondly, the excess mortality was highest in relation to accidents and violence (relative mortality $2 \cdot 51$ ). Mortality due to circulatory diseases among unemployed men was also high (relative mortality 1.54), but the excess mortality from cancer was slight and was accounted for mostly by deaths from lung cancer. Finally, the effects of unemployment on mortality were more pronounced with the duration of unemployment.

This study of unemployment and mortality would be enhanced by collecting information on the duration of unemployment for the whole follow up period. This would give more precise information about the effects of unemployment and might also make it possible to evaluate the effects of re-employment. Some questions, however, cannot be answered by using census data. Longitudinal studies on the mechanisms between unemployment and mortality are thus urgently needed. For example, we should know more about the change in behaviour and psychological stress that occur in people who become unemployed.

These analyses are part of a mortality research project headed by Professor Tapani Valkonen at the University of Helsinki. The project is supported by a grant from the Medical Research Council at the Academy of Finland. I am grateful to the Central Statistical Office of Finland for access to data (permission No TK-53-69-87) and to Seppo Koskinen, Tuija Martelin, Tapani Valkonen, and Eero Lahelma for helpful suggestions on earlier drafts.

1 Moser KA, Fox AJ, Jones DR. Unemployment and mortality in the OPCS longitudinal study. Lancet 1984;ii: 1324-9.

2 Fox AJ, Shewry MC. New longitudinal insights into relationships between unemployment and mortality. Stress Medicine 1988;4:11-9.

3 Moser KA, Fox AJ, Jones DR, Goldblatt PO. Unemployment and mortality: further evidence from the OPCS longitudinal study 1971-81. Lancet 1986; ; 365-6.

4 Moser KA, Goldblatt PO, Fox AJ, Jones DR. Unemployment and mortality: comparison of the 1971 and 1981 longitudinal study census samples. $\mathrm{Br} \mathrm{Med} \mathcal{F}$ 1987;294:86-90.

5 Iversen L, Andersen $\mathrm{O}$, Andersen PK, Christoffersen $\mathrm{K}$, Keiding $\mathrm{N}$. Unemployment and mortality in Denmark, 1970-80. Br Med $\mathcal{F} 1987 ; 295$ : 879-84

6 Stern J. The relationship between unemployment, morbidity and mortality in Britain. Population Studies 1983;37:61-74.

7 Vähätalo K. Työttömät ja työttömyysturvauudistus [The unemployed and the reform of unemployment security]. Helsinki: Työvoimaministerio, 1988. reform of unemployment securty). Helsinki: Työvoiman
(Työvoimapolittisia tutkimuksia, No 74.) (In Finnish.)

8 Valkonen T. Social inequality in the face of death. In: Plenary session of European population conference 1987. Helsinki: Tilastokeskus, 1987:201-61.

9 Brenner MH. Mortality and national economy. A review, and the experience of England and Wales, 1936-76. Lancet 1979;ii:568-73.

10 Payne CD, ed. The GLIM system. Release 3.77 manual. Oxford: Numerical Algorithms Group, 1985.

11 Haapakoski J. Toteutumien analysointi regressiomallin avulla [Analysis of events with the help of a regression model]. Sosiaaliläaketieteellinen Aikakauslehti 1983;20:195-202.

12 Valkonen T, Martelin T. Occupational class and suicide: an example of the elaboration of a relationship. Helsinki: Department of Sociology, University of Helsinki, 1988. (Research report No 222.)

3 Kreisky Commission on Employment Issues in Europe. A programme for full employment in the 1990s. Oxford: Pergamon Press, 1989.

14 Lahelma E. Unemployment, re-employment and mental well-being. Scandinavian foumal of Medicine 1989; suppl 43:1-170.

15 Martelin T. Development of smoking habits in Finland. Helsinki: National Board of Health, 1984. (Original report series, No 1.) (In Finnish; English summary.)

(Accepted 4 fune 1990)

\section{ONE HUNDRED YEARS AGO}

The ultimate results of some most interesting experiments which have been in progress for some years in the States of Massachusetts and New York will be watched with much interest by all persons interested in prison discipline. At the Concord Reformatory (Massachusetts) and the Elmira Reformatory (New York) convicts under 40 years of age are received, and are given the advantages of very considerable educational facilities. Regular classes for instruction are held in political economy, music, architectural drawing, mathematics, and other branches. There are periodical examinations, which furnish a basis for the apportionment of good marks, which materially expedite the periods of liberation. In this way the maximum period of detention, which is only five years, may be reduced to eleven months. Recreations of various kinds are provided, debating societies, scientific and literary clubs, printing presses, and weekly newspapers. The physical side is not neglected, for at Concord there is a farm of 160 acres, and at Elmira a very fine gymnasium was recently opened. It is a separate building, 140 feet long and 100 wide, equipped with all the most approved apparatus for physical culture, including, according to the Boston Medical and Surgical fournal, Russian and Turkish baths. After this, it is not surprising to learn that these prisons are exceedingly costly. (British Medical Fournal 1890;i:852.) 